\title{
Şeftali ve Ayva Yapraklarında Nem Miktarının Dielektrik Parametreleri Üzerindeki Etkisinin İncelenmesi
}

\author{
İbrahim Bahadır BAŞYİĞİT ${ }^{{ }^{*}}$ \\ ${ }^{1}$ Elektrik-Elektronik Mühendisliği, Teknoloji Fakültesi, Isparta Uygulamalı Bilimler Üniversitesi, Isparta, Türkiye \\ ${ }^{* 1}$ bahadirbasyigit@isparta.edu.tr
}

(Geliş/Received: 05/09/2019;

Kabul/Accepted: 03/02/2020)

Öz: Günümüzde tarım sektöründe, ürünün verim ve kalitesini artırmak için uzaktan algılama ve otomasyon sistemlerinin kullanımı artmaktadır. Mikrodalga 1sıtma/kurutma ve uzaktan izleme/kontrol uygulamalarında kullanılan teknolojilerde temel belirleyici parametrelerden biri, bitkilerin dielektrik özellikleridir. Bu nedenle, bu uygulamalarda kullanılacak sistemlerin doğru çalışması için bitkisel malzemelerin dielektrik karakteristiklerinin belirlenmesi önem arz eder. Bu çalışmada Isparta bölgesinde yoğun olarak üretilen şeftali ve ayva ağaçlarının yapraklarına ait dielektrik parametreler Dalga Kılavuzu İletim Hattı yöntemiyle ölçülmüştür. Ölçümler 3,30-4,90 GHz arasında (WR229 dalga kılavuzu için) yapılmış ve yaprakların dielektrik karakteristikleri nem içeriği ve frekansa bağlı olarak incelenmiştir. Şeftali yapraklarının dielektrik ölçüm verileri kullanarak frekans ve nem içeriğine (NI) bağlı, eğri uydurma yöntemiyle yeni bir model önerilmiştir. Bu model, şeftali türüyle aynı aileden olan ayva yaprağının dielektrik ölçüm sonuçlarıyla karşılaştırılarak önerilen modelin doğruluğu test edilmiștir. Modelin performansını görmek için regresyon katsayısı $R^{2}$ ve Hataların Ortalama Kare Kökü (RMSE) değerleri sırasıyla 0,995 ve 0,755 olarak elde edilmiştir.

Anahtar kelimeler: Dielektrik ölçümü, uzaktan algılama, nem içeriği, şeftali yaprağı, ayva yapră̆ı.

\section{Investigation of the Moisture Content Effect on Dielectric Parameters in Peach and Quince Leaves}

\begin{abstract}
Today, in the agricultural sector, the use of remote sensing and automation systems is increased to increase the yield and quality of the product. One of the main determinant parameters in the technologies used in microwave heating/drying and remote monitoring/control an application is the dielectric properties of plants. Therefore, it is important to determine the dielectric characteristics of plant materials for proper operation of the systems to be used in these applications. In this study, dielectric parameters of the peach and quince leaves produced in Isparta region are measured by Waveguide Transmission Line Method. Measurements are conducted between 3.30-4.90 GHz (for WR229 waveguide) and the dielectric characteristics of the leaves are examined depending on the moisture content and frequency. A new model with a curve fitting method based on frequency and moisture content (MC) is proposed used dielectric measurement data of peach leaves. This model is compared with the dielectric measurement results of quince leaves which belong to the same family with peach type to see the accuracy of the proposed model is tested. To obtain the performance of the model, the coefficient of regression $\mathrm{R}^{2}$ and Mean Square Root of Errors (RMSE) are obtained as 0.995 and 0.755 , respectively.
\end{abstract}

Key words: Dielectric measurement, remote sensing, moisture content, peach leaf, quince leaf.

\section{Giriş}

Tarım sektöründe geleneksel tekniklerin yerine, 1sıtma/kurutma ve uzaktan algılama (UA) gibi mikrodalga temelli yeni yöntemlerin kullanılmasıyla birlikte tarımsal ürünlerin verim ve kalitesi gün geçtikçe artmaktadır. Bu uygulamalardaki motivasyon, bitkilere zarar vermeden onların dielektrik parametrelerini belirlemek ve hem bitkilerin su ihtiyacını gidermek hem de meyvelerin kalitesini arttırmaktır [1, 2]. Çünkü bitkilerin yetersiz sulanması bitkinin ölümüne kadar gidebilecek problemlere yol açarken, aşırı sulanması da bitkilerde su azlığına karşı geliştirilen direncin kırılmasına, zararlı bitki böceklerinin çoğalmasına ve toprağın havasız kalmasına neden olabilmektedir [3, 4]. Bu amaçla bitkilerin su ihtiyacının tam olarak belirlenmesi ve sulama işlemlerinin otomasyon sistemleriyle gerçekleştirilmesi verim artışında önemli rol oynamaktadır. Dolayısıyla, bitkilerin yaprak, dal, meyve gibi kısımlarının içerdiği su miktarının bitkinin dielektrik özellikleri üzerindeki etkisini belirlemek önem arz eder. Ayrıca bitkilere zarar vermeden kısımlarındaki su miktarının belirlenmesi, meyvelerinin ne kadar olgunlaştığı ve meyvelerin kalitesi hakkında da fikir verebilir [5].

\footnotetext{
* Sorumlu yazar: bahadirbasyigit@isparta.edu.tr. Yazarların ORCID Numarası: ${ }^{1}$ 0000-0003-4558-5068
} 
Bitki kümesine gelen elektromanyetik (EM) dalgaları, bitkilerin yaprak, gövde, dal ve meyve yüzeylerine nüfuz eder ve yüzeyde yansıma, kırılma, soğurulma ve saçılma gibi EM davranışları gerçekleşir. Dielektrik parametreler, malzemelerin EM dalgalarla etkileşimini belirleyen en önemli parametrelerdendir. Genel olarak, homojen, yön bağımsız ve kayıplı bir ortam için kompleks dielektrik sabiti Denklem 1'de verilmiştir.

$\varepsilon^{*}=\varepsilon^{\prime}-j \varepsilon^{\prime \prime}$

Burada $\varepsilon^{\prime}$ dielektrik geçirgenliğin reel kısmı olup, gelen EM dalganın malzeme içerisinde depo edilebilme kabiliyetini temsil ederken, $\varepsilon^{\prime \prime}$ ise dielektrik geçirgenliğin sanal kısmı olup, malzeme içindeki kayıpları temsil eder. Malzeme içindeki kayıpları ifade eden bir diğer tanım kayıp tanjantıdır ve Denklem 2'de ifade edilmiştir.

$\tan \delta=\frac{\varepsilon^{\prime \prime}}{\varepsilon^{\prime}}=\frac{\sigma}{\omega \varepsilon_{\mathrm{r}} \varepsilon_{0}}$

Burada $\varepsilon_{0}$ boşluğun dielektrik sabiti olup, $\sigma$ iletkenlik, $\omega$ açısal frekans ve $\varepsilon_{r}$ bağıl dielektrik geçirgenlik sabitidir.

Bitkilerde dielektrik parametre ölçümlerinin 1910'lu yıllara başlamasına rağmen [6] son y1llarda bu konuda yapılan çalışmalar artmıştır. İlk çalışmalarda genelde kapasitif ölçme tekniği kullanılarak bitkilerin dielektrik özellikleri belirlenirken [7], sonraki çalışmalarda daha geniş frekans aralıklarında mikrodalga ölçüm yöntemleri kullanılarak birçok ürünün dielektrik parametreleri ortaya konulmuştur. Bu yöntemler sayesinde, özellikle meyvelerin depolanmasına yönelik ölçümler yapılmıș olup [5, 8], bitkilerin 1sıtma/kurutma süreçlerinde de bu yöntemlerin kullanılmıştır [9, 10]. Mikrodalga 1sıtma/kurutma işlemleri ile yoncalardan zararlı böcekleri arındırmaya yönelik çalışmalar da yapılmıştır. Yonca bitkisinin yanı sıra tahıl ürünlerinden buğday ve mısır üzerine yoğun bir şekilde çalışmalar yapılmıştır $[1,3]$. Bitkilerin sap ve yaprakları dielektrik parametreler açısından incelenerek çeşitli saçılma modelleri geliştirilmiştir [2]. Mısır ve domates yaprakları hem canlı [3,11] hem de dalından koparılarak dielektrik parametreleri ölçülmüş, bu yaprakların su ihtiyaçlarının gerçek zamanlı tahmini de yapılmıştır. Ayrıca bazı lifli bitkilerin, yapılarından dolayı polimer tabanlı soğurucu malzeme olarak kullanımı araştııılmış [12, 13], özellikle muz ağacı yapraklarının değişik karışımlarla birlikte soğurucu malzeme olarak kullanılma çalışmaları yapıllmıștır [14].

Şeftali ve ayva bitkilerinin her biri, Gülgiller (Rosacea) ailesi ve Rosales takımında bulunur. Türkiye, ayva üretiminde yıllık 135 bin tonluk kapasiteyle dünyada birinci, şeftali üretiminde ise ylllık 500 bin tonluk kapasiteyle dünyada altıncı sırada yer alır [15]. Bu ürünlerdeki verim ve kalitenin artırılmasına yönelik, hem UA ve ürün izleme otomasyonu hem de diğer mikrodalga uygulamaları için dielektrik parametrelerinin belirlenmesiyle ilgili çalışmalara ihtiyaç vardır ve bu çalışmadaki temel amaçtır.

$\mathrm{Bu}$ çalışmada, sabit sıcaklıkta nem içeriği (NI) ve frekansa bağlı olmak üzere birbiriyle aynı aileden olan şeftali ve ayva yapraklarının dielektrik karakteristikleri ölçüm sonuçlarıyla elde edilmiştir. Şeftali yapraklarının dielektrik ölçüm verileri kullanarak eğri uydurma yöntemiyle yeni bir model önerilmiștir. Bu model şeftali türüne akraba olan ayva yaprağıyla ilgili dielektrik ölçümleriyle modelin doğruluğu test edilmiştir. Bu çalışmada şeftali yaprağından farklı olarak ayva yaprağının seçilmiştir. Çünkü aynı aile grubunda bulunan iki farklı bitki türüne ait yaprakların birbirleri arasındaki ilişkiyi tespit etmek amaçlanmıştır. Ölçümlerde dalga kılavuzu iletim hattı tekniği kullanılmıştır. Ölçümler WR229 dalga kılavuzuyla 3,30-4,90 GHz frekans bandında yapılmıştır. Çalışmanın 2. bölümünde kullanılan dielektrik ölçüm yöntemi verilmiştir. 3. bölüm, elde edilen ölçüm sonuçları ve önerilen modelden oluşur ve 4 . bölümde sonuçlar değerlendirilmiştir.

\section{Dielektrik Ölçüm Yöntemi}

$\mathrm{Bu}$ çalı̧̧mada dielektrik parametrelerin belirlenmesi amacıyla dalga kılavuzu iletim hattı yöntemi kullanılmıştır. Bu yöntemde, frekans bandına göre ilgili dalga kılavuzu seçilmelidir. Ölçümler için dalga kılavuzu, Vektör Network Analizör'e (VNA) RF koaksiyel kabloyla bağlanmıștır. Alıcı ve verici durumunda olan iki dalga kılavuzu ve buna uyumlu bir adet flanş kullanılmıştır. Ölçülecek numune, flanş arasına konularak ölçüme hazır hale getirilmiştir. Ölçümler 3.30-4.90 GHz aralığında yapılmıştır. Bunun için frekans bandıyla uyumlu WR229 dalga kılavuzu seçilmiştir. VNA olarak Anritsu MS4624B modeli (10 MHz - $9 \mathrm{GHz})$ kullanılmıştır.

Ölçümlerde kullanılan numunelerin (yapraklar) kurutma aşamasında oluşan kıvrılmaları ve kırılmaları engellemek, dielektrik ölçümün doğruluğu için önemlidir. Bundan dolayı bu olumsuz etkiyi ortadan kaldırmak için yaprakların her iki tarafında, flanş ebatlarına uygun şeffaf plastik camlar (plexi glass) kullanılmıştır. Kullanılan şeffaf plastik camların dielektrik ölçümünde az da olsa etkisinin olduğu gözlenmiștir ve bu çalışmada 
plastik camın ölçüm üzerinde etkisi dikkate alınmıştır. Yaprakların homojen olarak kurutulmasını sağlamak amacıyla Bilgisayarlı Sayısal Kontrol (CNC) yöntemiyle plastik cam üzerinde eşit mesafede $8 \times 4$ sayıda bir mm'lik delikler açılmıştır. Numuneler, ölçümden önce 48 saat boyunca saf suda bekletilerek suya doymuş hale getirilmiştir. Numunelerin suda bekletildiği bu süre içerisinde ağılıkları her 12 saatte bir ölçülmüştür. 48. saat sonundaki ağırlık ölçümlerinde değişimin $\pm \% 0,3$ olduğu saptanmıştır. Ölçümler suda bekletilen 48 saatlik sürenin hesaba katılmadığı durumda yaprak başına yaklaşık üçer gün sürmüştür.

Ölçüme başlamadan önce suya doymuş yapraklar WR229 dalga kılavuzu boyutları için neşterle kesilmiştir. Numunelerin $S_{11}$ ve $S_{21}$ değerleri ölçülmüştür ve her ölçüm sonrasında mg hassasiyetine sahip hassas teraziyle ağırlıkları ölçülmüştür. Suya doymuş yapraklar mikrodalga fırında adım adım kurutulmuştur. Kurutma ve ölçüm adımları, yapraklar tamamen kuruyana kadar devam etmiştir. Son kurutma aşamasından sonra, firın içerisindeki sıcaklık $70^{\circ} \mathrm{C}$ iken numuneler bu ortamda 24 saat bekletilmiştir. Daha sonra tamamen kuruyan numunelerin ağırlık ve S-parametreleri alınarak ölçüm süreci tamamlanmıştır. Numunelerin ölçüm yapıldığı ortamda oda sıcaklığının $24^{\circ} \mathrm{C}$ olduğu not edilmelidir.

Şekil 1'de ölçüm ortamı görülmektedir. Şekil 1a'da dalga kılavuzlarıyla beraber ölçüme hazır olan sistem verilmiştir. Şekil 1b ve Şekil 1c, sırasıyla içi boş ve içi plastik camla dolu flanşları göstermektedir. Şekil 1d şeftali yaprağını, Şekil 1e ise ayva yaprağını göstermektedir.

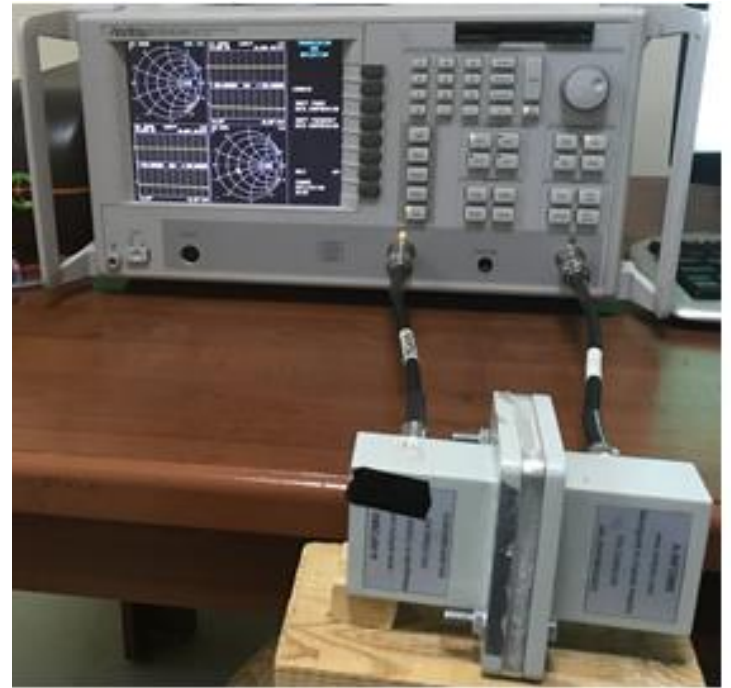

(a)

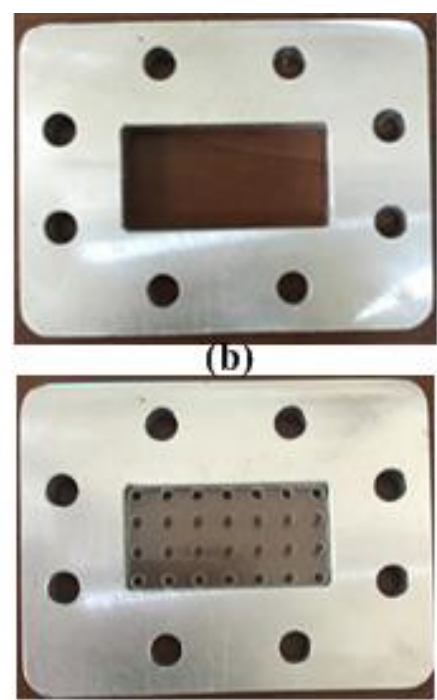

(c)

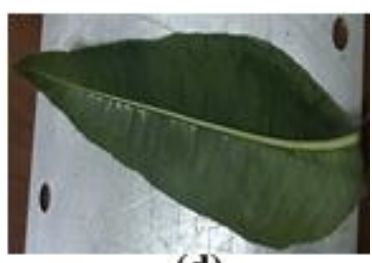

(d)

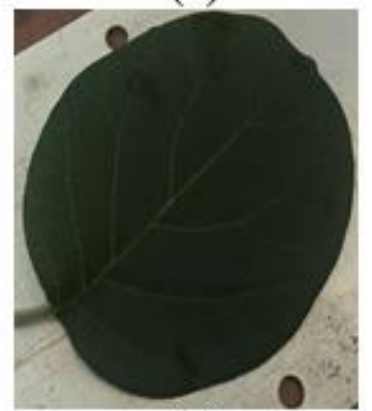

(e)

Şekil 1. Ölçüm ortamı

Daha önce belirtildiği gibi yaprakların kurutulma süreci adım adım gerçekleşmiştir. Tablo 1'de şeftali ve ayva yapraklarının WR229 için yapılan kurutma aşamalarında hesaplanan Nİ değerleri verilmiştir. Kurutma işlemine geçmeden önce suya doymuş şeftali yaprağının ağırlığının $368 \mathrm{mg}$ olduğu belirlenmiştir. Kurutmanın her adımında şeftali yaprağının ağırlığı düşerek 126 mg'da sabit kalmıştır. $\mathrm{Bu}$ ağırlık, yaprağın fırında $70^{\circ} \mathrm{C}^{\prime}$ de 24 saat bekletilerek ve tamamen kurutulmuş olan ağırlığıdır. Bu ağırlık düşüşüne bağlı olarak Nİ de düşmüştür. Suya doymuş ayva yaprağının ağırlığı 372 mg iken, tamamen kuru numune ağırlığı 147 mg'dır. Nİ değerleri \%100'den başlayarak adım adım azalarak \%0'a kadar düşmüştür. Suya doymuş şeftali ve ayva yapraklarının kurutulmadan önceki yüzde nem değeri \%100 iken, tamamen kuru yapraklardaki Ni ise \%0 olarak Denklem 3'e göre hesaplanmıştır [11].

Su miktarl $=m_{\text {doymuş }}-m_{\text {kuru }}$

$N O=\frac{m_{\ddot{o ̈ l c ̧ u ̈ l e n}}-m_{k u r u}}{\text { Su miktarl }}$

Burada $m_{\text {ölçülen }}$ her bir kurutma adımında numunenin ölçülen ağırlığı, $m_{\text {doymuş }}$ numunenin suya doymuş ilk ağırlığı ve $m_{k u r u}$ numunenin tamamen kurumuş son ağırlığıdır. Nem içeriği $(N \dot{I})$, Denklem 4 yardımıyla elde edilir. 
Tablo 1. Ölçümü WR229 (3,30-4,90 GHz) için yapılan yaprakların nem içeriği değişimi

\begin{tabular}{c|cccc|cccc}
\hline & \multicolumn{4}{|c|}{ Şeftali yaprağı } & \multicolumn{4}{c}{ Ayva yaprağı } \\
\hline $\begin{array}{c}\text { Zaman } \\
(\mathrm{sn})\end{array}$ & $\begin{array}{c}\text { Toplam } \\
\text { ağırlık } \\
(\mathrm{mg})\end{array}$ & $\begin{array}{c}\text { Kurumus } \\
\text { ağırlı } \\
(\mathrm{mg})\end{array}$ & $\begin{array}{c}\text { Nem miktarı } \\
(\mathrm{mg})\end{array}$ & $\begin{array}{c}\text { Yüzde nem } \\
\text { değeri } \\
(\%)\end{array}$ & $\begin{array}{c}\text { Toplam ağırlık } \\
(\mathrm{mg})\end{array}$ & $\begin{array}{c}\text { Kurumuş } \\
\text { ağırlı } \\
(\mathrm{mg})\end{array}$ & $\begin{array}{c}\text { Nem miktarı } \\
(\mathrm{mg})\end{array}$ & $\begin{array}{c}\text { Yüzde nem } \\
\text { değeri } \\
(\%)\end{array}$ \\
\hline 20 & 368 & 126 & 242 & 100 & 372 & 147 & 225 & 100 \\
40 & 219 & 126 & 93 & 38.43 & 240 & 147 & 93 & 41.33 \\
60 & 168 & 126 & 42 & 17.36 & 183 & 147 & 36 & 16 \\
80 & 145 & 126 & 19 & 7.85 & 169 & 147 & 22 & 9.78 \\
100 & 139 & 126 & 13 & 5.37 & 159 & 147 & 12 & 5.33 \\
120 & 126 & 126 & 0 & 0 & 147 & 147 & 0 & 0 \\
\hline
\end{tabular}

Nİ değerinin dielektrik sabiti üzerindeki etkisini görebilmek için ölçülen S-parametrelerinden bağıl dielektrik sabiti $\left(\varepsilon^{\prime}\right)$ ve dielektrik kaybın $\left(\varepsilon^{\prime \prime}\right)$ hesaplanması gerekir. Literatürde bu durumla ilgili farklı algoritmalar olsa da en çok bilinen ve kabul gören yöntem Nicolson-Ross-Weir (NRW) algoritmasıdır [16, 17]. Bu çalışmada NRW algoritması kullanılarak yaprakların dielektrik parametreleri hesaplanmışıtır. Bu yöntemle elde edilen dielektrik parametrelerinin doğru hesaplanması için iki durum göz önünde bulundurulmalıdır. Bunların ilki, yaprakların belli kalınlığa sahip olmasıdır. Diğeri ise ölçüm hatalarının hassasiyeti frekans yükseldikçe arttığından dolayı hataları en aza indirmek için ölçüm ve test hazırlığının dikkatli yapılmasıdır. Denklemler 5-12 kullanılarak NRW algoritmasıyla dielektrik geçirgenlik sabiti hesaplanır. $\mathrm{S}_{11}$ değeri, giriş portundan yansıyan gerilim dalgasının, aynı porta giren gerilim dalgasının oranı olarak tanımlanır. $\mathrm{S}_{21}$ değeri ise, çıkış portundan çıkan gerilim dalgasının, giriş portuna giren gerilim dalgasının oranı olarak tanımlanır.

$S_{11}=\frac{\Gamma\left(1-T^{2}\right)}{\left(1-\Gamma^{2} T^{2}\right)}$

$S_{21}=\frac{T\left(1-I^{2}\right)}{\left(1-I^{2} T^{2}\right)}$

Burada, $\Gamma$ yansıma katsayısı iken, $T$ iletim katsayısıdır.

$X=\frac{S_{11}^{2}-S_{21}^{2}+1}{2 S_{11}}$

$\Gamma=X \pm \sqrt{X^{2}-1}$

$T=\frac{S_{11}+S_{21}-\Gamma}{1-\left(S_{11}+S_{21}\right) \Gamma}$

$L$, numunenin kalınlı̆̆ıdır. Manyetik olmayan malzemelerde $\mu_{r} \approx 1$ olarak alınır ve bu çalışmada ölçümü yapılan yapraklar manyetik malzeme olmadığı için NWR hesaplamalarında $\mu_{r} \approx 1$ alınmıştır [18]. Numune kalınlığının $L$ olmak üzere numunenin bağıl manyetik geçirgenliğini $\left(\mu_{r}\right)$ hesaplamak için Denklem 11 kullanılır. Denklem 11 ise $\lambda_{0}$ ve $\lambda_{c}$ sirasıyla serbest uzay ve kesim frekansındaki dalga boyu olmak üzere numunenin bağıl dielektrik geçirgenliği $\left(\varepsilon_{r}\right)$ hesaplanır.

$$
\begin{gathered}
\frac{1}{\Lambda^{2}}=-\left[\frac{1}{2 \pi L} \ln \left(\frac{1}{T}\right)\right]^{2} \\
\varepsilon_{r}=\frac{\lambda_{0}}{\mu_{r}}\left(\frac{1}{\lambda_{c}^{2}}-\left[\frac{1}{2 \pi L} \ln \left(\frac{1}{T}\right)\right]^{2}\right)
\end{gathered}
$$




\subsection{Sistematik Hataların Ortadan Kaldırılması}

Ölçüm düzeneğindeki sistematik hataların giderilmesi için yaygın olarak kullanılan yöntemler, gömülü (embedding) ve Doğrudan Yansıma Hattı (Thru Reflect Line) yöntemleridir. Gömülü yöntem, testte kullanılan modelin hatalarını yok etmek için matematiksel ifadelerden yararlanır. Bu yöntem, modellerde kalibrasyon tekniklerinin kullanılmadığı koaksiyel olmayan cihazlarda tercih edilir [19] ve S-parametrelerinden yararlanır. Bundan dolayı bu yöntem, modeldeki hataların testi yapılmadan uygulanamaz. Dielektrik ölçümlerinde kullanılan plastik camlar, Test Altındaki Cihaz (Equipment Under Test) gibi davrandığı için ölçümlerde bu plastik camların S-parametrelerinin belirlenmesi gerekir. Dolayısıyla hem flanş hem de bu plastik camların dielektrik ölçüm üzerindeki etkileri giderilmelidir. Bu durumun literatürdeki yöntemlerle [20] uyumlu olmasına dikkat edilmelidir.

Gömülü yöntemlerin yanı sıra, dielektrik ölçümlerde oluşabilecek hataları en aza indirmek için farklı türde kalibrasyon yöntemleri vardır. Bunların arasında Doğrudan Yansıma Hattı Yöntemi, yaygın olarak kullanılan ve doğru sonuçlar veren bir yöntemdir [21]. Bu teknik, ölçüm yöntemlerindeki doğruluğu gösterebilen bir referans yöntem olarak da bilinir. Bu yüzden, bu yöntemin doğruluğunu doğrudan etkileyebilecek hataların kaynakları dikkate alınmalıdır. Düşük frekanslarda ihmal edilen hata oranları, yükssek frekanslarda ölçüm doğruluğunu daha fazla etkiler.

\section{2. Ölçüm ve kalibrasyon yöntemini doğrulama testi}

Teflon, dielektrik ölçüm doğruluğunda kolay ulaşılabilirliği ve düşük maliyetinden dolayı yaygın olarak kullanılan bir malzeme türüdür. Bu malzemenin $\varepsilon^{\prime}$ ve $\varepsilon^{\prime \prime}$ değerleri frekans değişimiyle neredeyse sabit olup, sırasıyla 2 ve 0 'dır. Bu çalışmada kalınlığı $2,5 \mathrm{~mm}$ olan teflon tabaka kullanılarak dielektrik parametrelerinin ölçümü yapılmıştır. Şekil 2 incelendiğinde teflon malzemenin ölçülen $\varepsilon^{\prime}$ ve $\varepsilon^{\prime \prime}$ değerlerinin teorik sonuçlara yakın olduğu görülmektedir. Bu sonuçlara göre, çalışmadaki test düzeneği ve kalibrasyon yönteminin doğruluğu tespit edilmiştir.

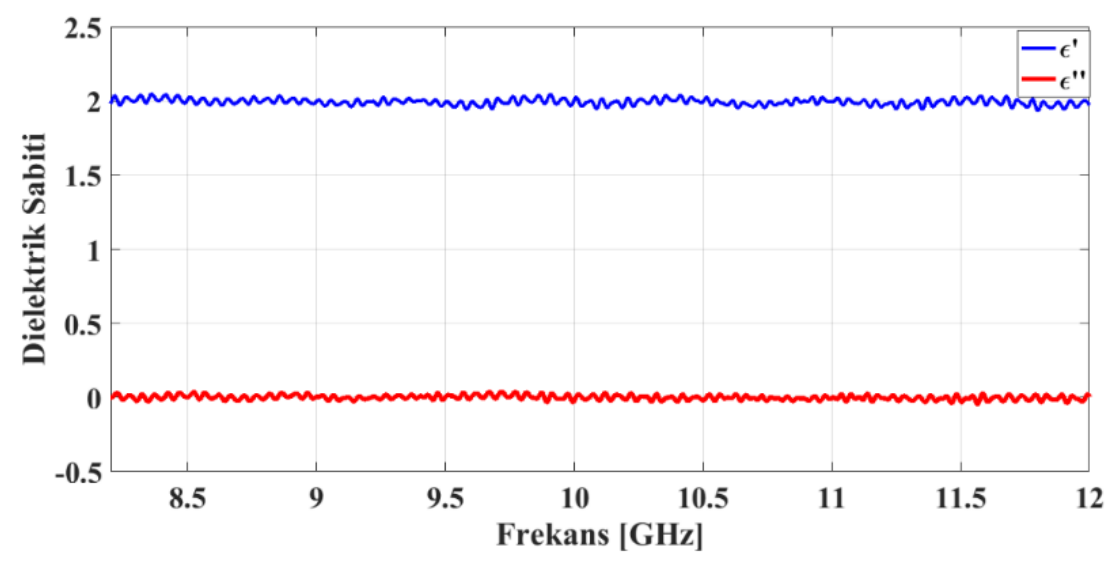

Şekil 2. 2,5 mm kalınlığındaki teflon için ölçülen dielektrik parametreler

\section{3. Ölçüm Sonuçları ve Önerilen Model}

Giriş bölümünde belirtildiği gibi ölçümlerde şeftali ve ayva yaprakları numune olarak kullanılmıştır. Dalga kılavuzu olarak 3,30-4,90 GHz frekans bandına uyumlu WR229 dalga kılavuzu kullanılmıştır. Her bir numune için $\varepsilon^{\prime}$ ve $\varepsilon^{\prime \prime}$ değerleri $24^{\circ} \mathrm{C}$ oda sıcaklığında, frekans ve Ni değerlerine bağlı olarak ölçülmüşstur. VNA'dan elde edilen $S_{11}$ ve $S_{21}$ değerleri ve 2 . Bölüm'de bahsedilen NRW algoritması kullanılarak $\varepsilon^{\prime}$ ve $\varepsilon^{\prime \prime}$ değerleri hesaplanmıştır. Bu frekans bandı için ölçüm adım sayısı 2 MHz olup 801 farklı frekans noktasında ölçüm yapılmıştır.

Şekil 3 'te şeftali yaprakları için ölçülen $\varepsilon^{\prime}$ değerleri verilmiştir. $\varepsilon^{\prime}$ değerinin, frekans azalışı ve Nİ artışı ile arttığı gözlenmiştir. Bu benzer değişimlerin $\varepsilon^{\prime \prime}$ değerleri için de geçerli olduğu Şekil 4 'te görülmektedir. 


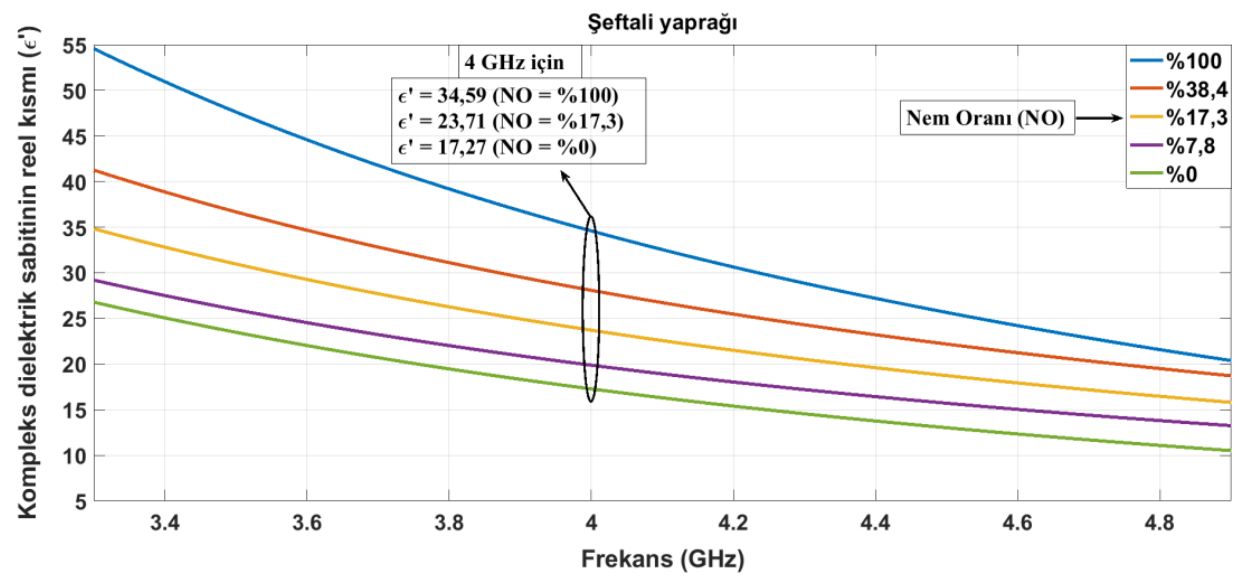

Şekil 3. Nem ve frekansa bağlı olarak şeftali yaprağının dielektrik özellikleri $\left(\varepsilon^{\prime}\right)$

Sekil 5 ve Şekil 6'da ayva yaprakları için elde edilen $\varepsilon^{\prime}$ ve $\varepsilon^{\prime \prime}$ değerleri verilmiştir. Frekansa bağlı olarak $\varepsilon^{\prime}$ ve $\varepsilon^{\prime \prime}$ değerleri, eksponansiyel olarak azalmaktadır. NI'ye bağlı olarak ise bu değerler dikey eksende azaldığı görülmüştür. Literatürde, saf suyun $\varepsilon^{\prime}$ değerleri, $3,30-4,90 \mathrm{GHz}$ bandı için 78-74 aralı̆̆ında değişmektedir [1]. Bu çalışmada elde edilen sonuçlar için suya doymuş yaprağın $\varepsilon^{\prime}$ ve $\varepsilon^{\prime \prime}$ değerleri, kuru yaprağınkine göre daha yüksektir ve bu durum NI'den dolayı beklenen durumdur.

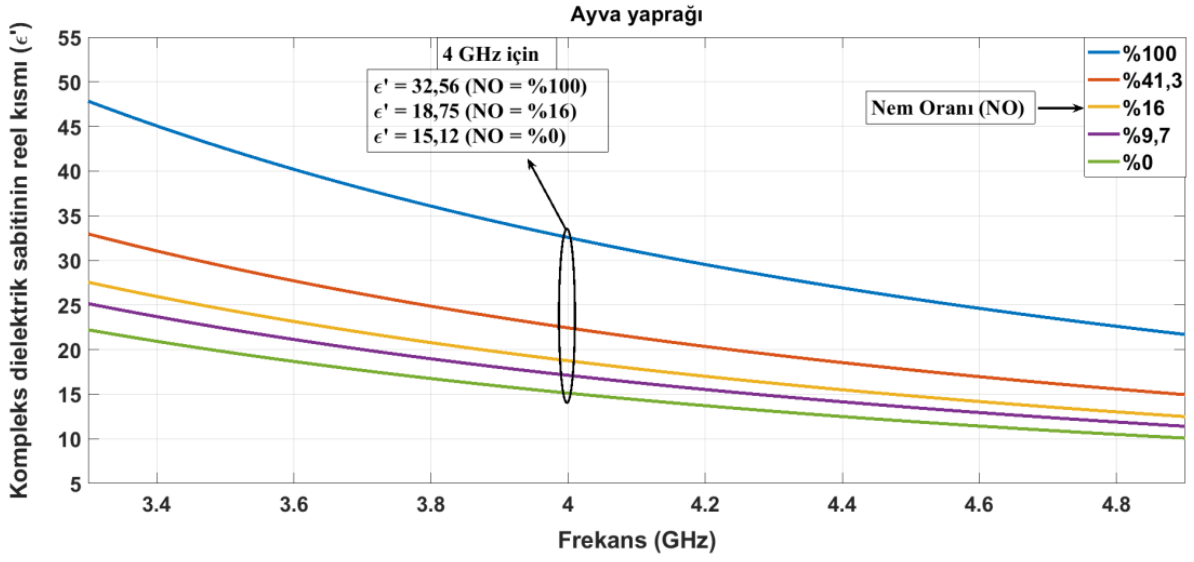

Şekil 5. Nem ve frekansa bağlı olarak ayva yaprağının dielektrik özellikleri $\left(\varepsilon^{\prime}\right)$

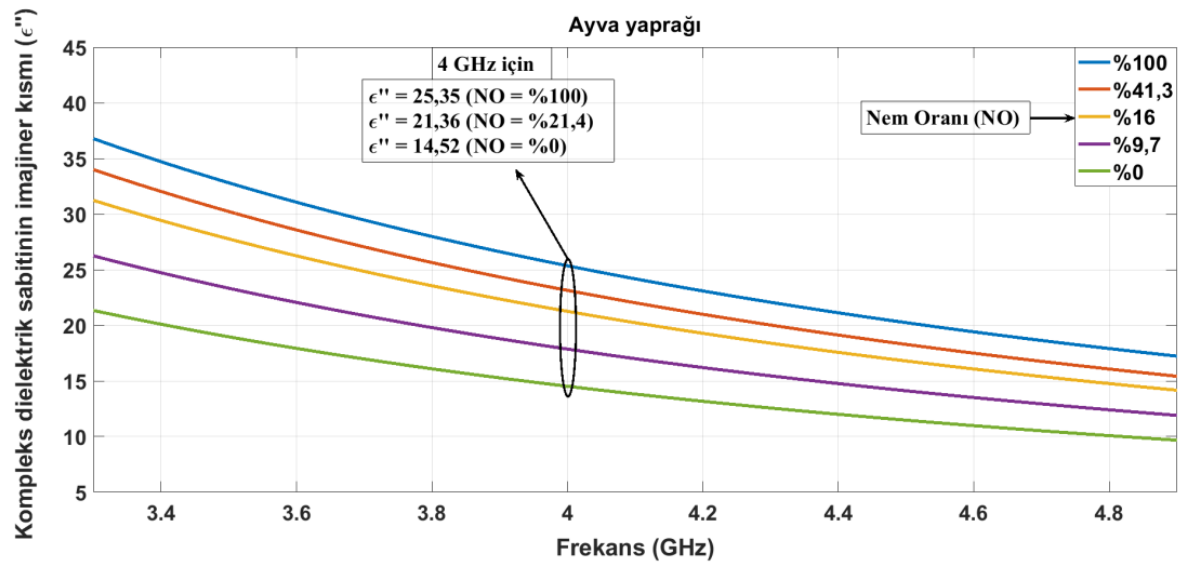

Şekil 6. Nem ve frekansa bağlı olarak ayva yaprağının dielektrik özellikleri $\left(\varepsilon^{\prime \prime}\right)$ 
Şeftali yapraklarının ölçüm sonuçlarından elde edilen veriler kullanarak eğri uydurma yöntemiyle yeni bir model elde edilmiştir. Bu modelle, sabit sıcaklıkta $\left(24^{\circ} \mathrm{C}\right)$ frekans ve Nİye bağlı dielektrik sabitini hesaplamak hedeflenmiştir. Denklem 15 'te verilen bu model, iki değişkenli ikinci dereceden bir kuvvet fonksiyonundan oluşur.

$\varepsilon_{r}(f, m)=a+b \cdot f^{-c}+d \cdot m^{e}+g \cdot f^{-c} * m^{e}$

$\varepsilon_{r}=\sqrt{\varepsilon^{\prime 2}+\varepsilon^{\prime \prime 2}}$

Burada, $\varepsilon_{r}$ dielektrik sabiti, $f \mathrm{~Hz}$ cinsinden frekans, $m$ 0-100 arasında değişen yüzde nem değeridir. Eşitlik 13'de verilen $\varepsilon_{r}$ değeri, malzemenin dielektrik sabitinin hem reel hem de sanal kısmını içerdiği için modelde tercih edilmiştir. Şeftali yaprağı için WR229'da elde edilmiş modelin katsayıları $a=0,216, b=379,1 \quad c=2,013, d=-0,369$, $e=0,4748, g=44,32$ şeklindedir. Bu modeli oluşturmak için, Tablo 1'de şeftali yaprağının WR229 için kurutma adımlarında hesaplanan 6 farklı MC veri olarak kullanılmıştır. Elde edilen modelin doğruluğunu test etmek için daha önce ölçümlerde kullanılan şeftali yapraklarından farklı ve \%29 nem içeriğine sahip başka bir şeftali yaprağı test numunesi olarak seçilmiştir. Önerilen modelin de aynı MC değerine sahip olması için Eşitlik 12'de verilen m değeri 29 olarak girilmiştir. Şekil 7'de önerilen model ile test için seçilen şeftali yaprağının ölçülen değerleri karşılaştırılmıştır. Sonuçların birbiri ile çok uyumlu olduğu görülmektedir. Modelin performansını görmek için $\mathrm{R}^{2}$ ve Root Mean Square Error (RMSE) değerleri de hesaplanmıştır. Buna göre modelin $\mathrm{R}^{2}$ ve RMSE değerleri, sirasiyla 0,995 ve $0,755^{\prime}$ dir.

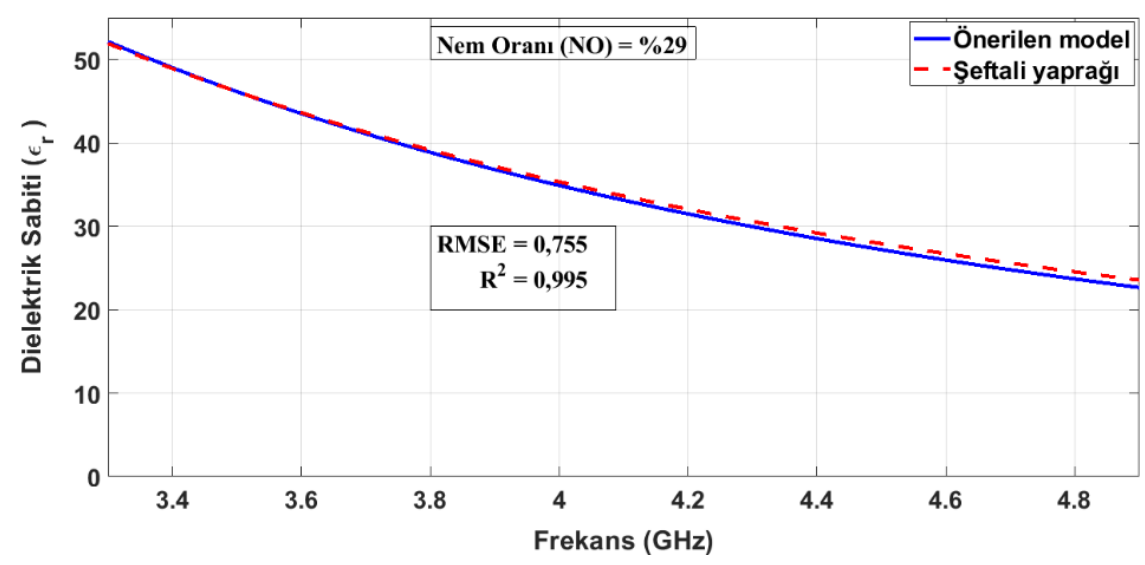

Şekil 7. Önerilen modelin şeftali yaprakları ile doğruluğunun test edilmesi

Şeftali yaprağına ait ölçüm verilerini kullanarak oluşturulan modelin ayva yaprağ için kullanılabilirliği test edilmiştir. Burada, Nİ değeri \%40 olan bir ayva yaprağı ile aynı Nİ değerine sahip $(m=40)$ önerilen modelin sonuçları karşılaştırılmıştır. Bu sonuçların birbiriyle çok uyumlu olduğu Şekil 8'de görülmüştür. Bu karşılaştırma, aynı akraba ve aynı aile içinde olan bir bitkinin yapraklarından elde edilen bir modelin aynı ailedeki diğer bitki türleri için uyumlu olabileceği hususunda fikir vermektedir. Şeftali ve ayva bitkilerinin her biri, Gülgiller (Rosacea) ailesi ve Rosales takımında bulunur. Bundan dolayı şeftali yaprağı ölçüm verileriyle elde edilen model, ayva yaprağı ölçüm sonuçlarıyla karşılaştırılmıştır. 


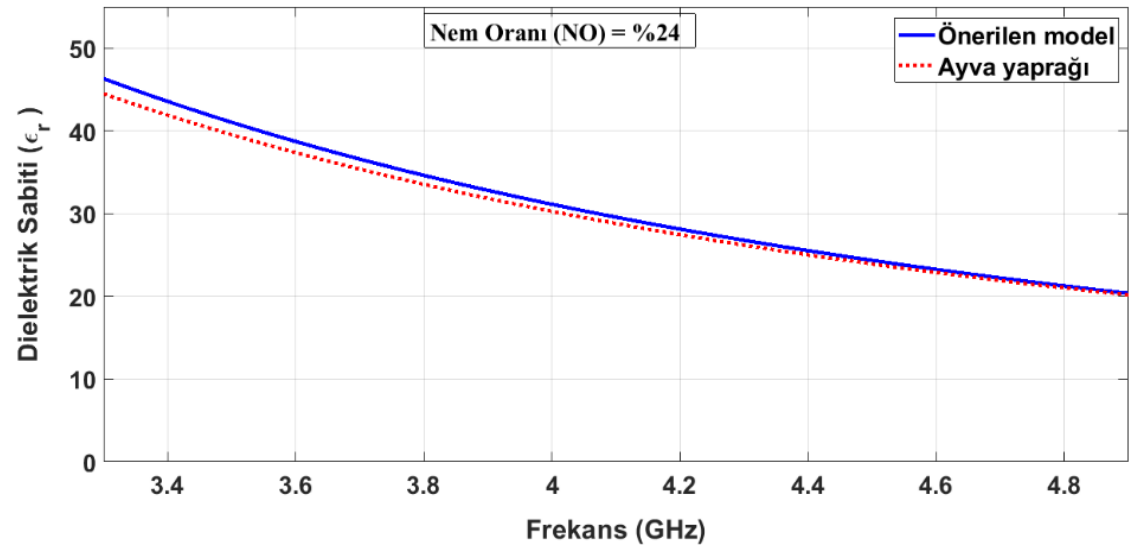

Şekil 8. Önerilen modelin ayva yaprakları ile doğruluğunun test edilmesi

\section{Sonuç ve Öneriler}

Bu çalışmada, sabit sıcaklıkta Nİ ve frekansa bağlı olmak üzere birbiriyle aynı aileden olan şeftali ve ayva yapraklarının dielektrik karakteristikleri ölçüm sonuçlarıyla elde edilmiştir. Şeftali yapraklarının dielektrik ölçüm verileri kullanılarak eğri uydurma yöntemiyle yeni bir model önerilmiştir. Şeftali türüne akraba olan ayva yaprağıyla ilgili dielektrik ölçümleriyle bu modelin doğruluğu test edilmiştir. Ölçümlerde dalga kılavuzu iletim hattı tekniği kullanılmıştır. Ölçümler WR229 dalga kılavuzuyla 3,30-4,90 GHz frekans bandında yapılmıştır. Bütün frekans bandında şeftali için $\varepsilon^{\prime}$ değerleri 11-55, $\varepsilon$ " değerleri ise 11-39 aralığında değiştiği tespit edilmiştir. Şeftali yapraklarının dielektrik ölçüm verileri kullanarak frekans ve nem içeriğine (NI) bağlı, eğri uydurma yöntemiyle yeni bir model önerilmiştir. Bu model, şeftali türüyle aynı aileden olan ayva yaprağının dielektrik ölçüm sonuçlarıyla karşılaştırılarak önerilen modelin doğruluğu test edilmiştir. Modelin performansını görmek için regresyon katsayısı $R^{2}$ ve Hataların Ortalama Kare Kökü (RMSE) değerleri sırasıyla 0,995 ve 0,755 olarak elde edilmiştir.

\section{Teșekkür}

Bu çalışmada ölçümlerin gerçekleştirildiği Akdeniz Üniversitesi Endüstriyel ve Medikal Uygulamalar Mikrodalga Araştırma Merkezi'nin verdiği ölçüm desteği için teşekkür ederim.

\section{Kaynaklar}

[1] Ulaby FT, Jedlicka R. Microwave dielectric properties of plant materials. IEEE T Geosci Remote 1984; (4): $406-415$.

[2] Chuah H, Kam S, Chye Y. Microwave dielectric properties of rubber and oil palm leaf samples: measurement and modelling. Int J Remote Sens 1997; 18(12): 2623-2639.

[3] Afzal A, Mousavi S.F. Estimation of moisture in maize leaf by measuring leaf dielectric constant. Int J Agricul Biol, 2008; 10: 66-68.

[4] Van Emmerik T, Steele-Dunne S, Judge J, van de Giesen N. A comparison between leaf dielectric properties of stressed and unstressed tomato plants. Int Geosci Remote Se 2015; 275-278.

[5] Nelson SO. Agricultural applications of dielectric measurements. IEEE T Dielect El In 2006: 13(4): 688-702.

[6] Nelson SO. Trabelsi S. Permittivity measurements and agricultural applications. Electromagnetic Aquametry 2005; 419-442.

[7] Jha SN, Narsaiah K, Basediya A, Sharma R, Jaiswal P, Kumar R, Bhardwaj R. Measurement techniques and application of electrical properties for nondestructive quality evaluation of foods - a review. J Food Sci 2011; 48(4): 387-411.

[8] Nelson SO. Dielectric properties of agricultural products-measurements and applications. IEEE T Electr Insul 1991; 26(5): 845-869.

[9] Kamaruddin MJ, Yusof M, Ngadi N, Zakaria Z, Arsad A, Kidam K. Dielectric Properties for Extraction of Orthosiphon Stamineus (Java Tea) Leaves. Chem Engineer Trans 2017; 56: 1771-177. 
[10] Trabelsi S, Mckeown MS, Nelson SO. Dielectric properties-based method for rapid and nondestructive moisture sensing in almonds. J Microwave Power EE 2016; 50(2): 94-105.

[11] Van Emmerik TH. Diurnal differences in vegetation dielectric constant as a measure of water stress, 2013; MSc, Delft University.

[12] Colak B. Moisture content effect of banana leaves to radio frequency absorbing. Microw Opt Techn Let 2019.

[13] Jayamani E, Hamdan S, Ezhumalai P, Bakri MK. Investigation on dielectric and sound absorption properties of banana fibers reinforced epoxy composites. Jurnal Teknologi, 2016; 78: 6-10.

[14] Kaur R, Aul GD, Chawla V. Improved reflection loss performance of dried banana leaves pyramidal microwave absorbers by coal for application in anechoic chambers. Prog Electromagn Res 2015, 43: 157-164.

[15] Sait HH, Salema AA. Microwave dielectric characterization of Saudi Arabian date palm biomass during pyrolysis and at industrial frequencies. Fuel 2015; 161: 239-247.

[16] Weir WB. Automatic measurement of complex dielectric constant and permeability at microwave frequencies. P IEEE 1974; 62(1): 33-36.

[17] Nicolson A, Ross G. Measurement of the intrinsic properties of materials by time-domain techniques. IEEE T Instrum Meas 1970; 19(4): 377-382.

[18] Yaw KC. Measurement of dielectric material properties: application note. Rhode \& Schwarz, 2012.

[19] De-embedding and Embedding S-Parameter Networks Using a Vector Network Analyzer, 2004; Application Notes.

[20] Helhel S, Kurnaz O. Buried metal detection within the wooden block by X-band measurements. Microw Opt Techn Let 2016; 58(5): 1245-1253.

[21] Ye L, Li C, Sun X, Jin S, Chen B, Ye X, Fan J. Thru-Reflect-Line Calibration technique: error analysis for characteristic impedance variations in the line standards. IEEE T Electromagn C 2016; 59(3): 779-788.

[22] Kumar A, Sharma S, Singh G. Measurement of dielectric constant and loss factor of the dielectric material at microwave frequencies. Prog Electromagn Res 2007; 69: 47-54. 